\title{
Supervisor Fuzzy Logic Controller for HVAC System of S.J Carew Building at Memorial University
}

\author{
Almahdi Abdo-Allah, M Tariq Iqbal, and Kevin Pope
}

\begin{abstract}
One of the most important characteristics contributing to the thermal management efficiency of commercial, industrial, institutional or home environments is the optimal functioning of HVAC (heating, ventilation, air conditioning) systems. In addition to using supervisor controllers for balancing comfort level in a building, the majority of today's HVACs employ nonlinear time variance controllers when dealing with a variety of disturbances. This paper investigates both current and potential HVAC systems at Memorial University's S. J. Carew building, St. John's, Newfoundland. The study investigates the viability of algorithmbased supervisor fuzzy logic controllers (SFLC) for the control of the building's four air-handling units (AHUs) used to manage the interior environment. Along with temperature, the SFLCs also control the AHUs' fan speeds and $\mathrm{CO}_{2}$ concentrations modifying hot water and air flow rates. This work presents models of damper positions, fan speeds and globe valves that have been built in accordance with current rates of air and hot water flow in the S. J. Carew building. Based on these specifications, a novel method of SFLC adaptation using fuzzy rules has been devised. The novel system aims to better balance the performance level of the Carew building's HVAC system on a floor-by-floor basis. The overall results indicate better overall thermal comfort levels and enhanced cost-effectiveness when using the SFLC redesign.
\end{abstract}

Index Terms - Modeling and simulation, HVAC system, IDA-ICC program, system identification, state space model, fuzzy logic, SFLC.

\section{INTRODUCTION}

The purpose of HVAC systems is to create comfortable and cost-efficient internal environments within structures. However, these systems must also be able to deal with constantly changing variables affecting their performance level. To accomplish this task, appropriate control systems are required, such as mathematics-based HVACs controllers. These approaches, which use input/output variable data to determine the parameters of individual systems, are able to refine and enhance HVAC systems through the process of system identification (SI) (ASHRAE, 2005) [1].

The thermal management efficiency of commercial, industrial, institutional and home environments relies, to a large extent, on the optimal functioning of their respective HVAC (heating, ventilation, air conditioning) systems. Air quality and thermal comfort levels are nearly entirely dependent on HVACs, and these systems also have a major role in a building's operational costs. In commercial or industrial structures, up to $50 \%$ of the building's overall energy use is contingent on how well the installed HVAC system is functioning [2-4]. In developed countries, mitigating pollution levels is almost equally as important as cost-effectiveness when it comes to heating and cooling systems, so there has been a recent surge in research that investigates combining renewable energy production with state-of-the-art HVAC systems [5].

A driving force behind the development of building intelligent energy management systems (BIEMS) in larger structures such as hotels and office buildings is the smart management of thermal comfort levels and the smart management of power costs. BIEMS enables buildings to essentially manage their own energy use by constant intelligent monitoring of the building's macroclimate. Based on the data, the operational parameters are then adjusted to suit the needs of the building's several microclimates. In research, as well as in practical application, BIEMS that use fuzzy techniques have consistently outperformed traditional control systems [6-8].

The main difference between intelligent systems (i.e., automatic controllers) and traditional control methods is that intelligent systems do not require a mathematical model to monitor and control a building's operations. Instead, intelligent systems, like PMV [9], use optimized fuzzy controllers based on adaptive control strategies and genetic algorithms. Fuzzy logic control is already being used for state-of-the-art furnace controllers in select homes. These controllers employ adaptive heating control to determine the best use of the available energy to achieve the desired comfort level [10]. Also, fuzzy controllers are currently being tested in real-life ventilation and thermal subsystems, giving promising results $[11,12]$.

Over the past thirty years, numerous HVAC experts have developed operational and control methods for specific applications. During the same timeframe, numerous research studies, textbooks and journal articles have also investigated various issues of HVAC operation and control, including the supervisor control technique (e.g., Honeywell [13]; Levenhagen and Spethmann [14] ; Wang and Jin [15]; Zaheer-uddin and Zheng [16]; Hordeski [17]; Haines and Hittle [18]; Nassif et al. [19]; Wang [20]; etc.). They classify the primary supervisory control approaches that are employed in HVAC systems into four different types of supervisory control methods: 1) model-based, 2) model-free, 3) performance map-based, and 4) hybrid [21].

In a study conducted by Kanagaraj, Sivashanmugam, and Paramasivam [22], the researchers investigated the tuning of input scaling factors for direct expert controllers by applying error and process input parameters for closed-loop systems. Their aim was developing improved controller performance in relation to load disturbances and set-point changes. In general, the on-line tuning strategy involves significantly decreased levels of operator input and dependency, while 
improving the performance of the controller across a broad operational spectrum. The approach, which is a form of hierarchical control, comprises the input of an intelligent upper-level supervisory fuzzy controller in tandem with a lower-level direct fuzzy controller. The task of the upperlevel controller is to introduce applicable mechanisms for the system's primary goals, while the task of the lower-level controller is to provide solutions for specific problems.

A few years later, Soyguder, Servet, Karakose, and Alli [23], used MATLAB / SIMULINK, to model expert HVAC systems that had variable flow-rates. They used fuzzy adaptive controllers that were self-tuning PIDs to demonstrate PID parameters for $\mathrm{kp}$, ki and $\mathrm{kd}$. The outcome of their tests showed that their novel control algorithm performed comparably to traditional PID, as well as fuzzyPD type controllers.

Shepherd and Batty [24], conducted experiments that employed a high-level fuzzy supervisor for control decisions. Their aim was to obtain optimal quality for indoor environments by using a modified fuzzy supervisor. Their approach also considered how issues around cost and energy efficiency can ultimately impact the decisions. From the outcomes of their simulation tests, the researchers determined that systems operation could be enhanced by applying their approach.

Lianzhong and Zaheeruddin [25], built a non-linear dynamic model for water heating HWDH systems. Their work also included intelligent fuzzy logic-based hybrid control methods. The researchers' simulation results suggest that fuzzy logic-based PI provides enhanced control and regulation of return temperature of water, particularly, when combined with IATP strategies for controlling air temperature within a specific zone. The researchers noted a $17 \%$ improvement in energy savings through reduced consumption.

Hussain, Sajid, and Gabbar [26], attempted to improve energy consumption outcomes by tuning an FLC via GAs. Using a novel air conditioner, the researchers succeed in saving approximately $15 \%$ compared to strategies that simply employ an ON-OFF control method. They noted no increase either in the discomfort index / dissatisfaction levels but instead recorded a significant reduction, falling to $62 \%$ from a high of $91 \%$. Meanwhile, in [27], dual-level controllers (lower-level and higher-level) are presented and tested. The lower level controller comprises a traditional PID-type controller, whereas the higher-level controller comprises a fuzzy controller which acts over the low-level controller's parameters.

Using these and other research outcomes as an inspiration for the present research, this work investigates a fuzzy level control method that controls outputs for four AHUs to maintain $\mathrm{CO}_{2}$ concentrations, static air pressure, and zonal temperatures. The aim is to determine the best approach for fuzzy control methods to perform the desired actions required for each parameter, on a parameter-by-parameter basis. The proposed fuzzy supervisor will be able to decide whether a certain desired action is or is not in the best interest of the entire system (in terms of overall performance). The fuzzy supervisor might also be given control over aspects of energy savings that better balance a building's overall heating and cooling system's performance levels, taking the needs of each floor into consideration.

\section{CASE STUDY}

The present paper employs as a case study the S. J. Carew building, which is located on the campus of Memorial University, St. John's, Newfoundland. The building is currently used to house the Faculty of Engineering and Applied Science at Memorial and is divided into numerous lecture rooms and labs. There is also a large cafeteria space. Interiorly, the Carew building measures approximately $25,142 \mathrm{~m}^{2}$ and features four individual air-handling units for the building's 300+ zones. Table 1 lists an energy report for the Carew building, while Figure 1 depicts a 3D model.

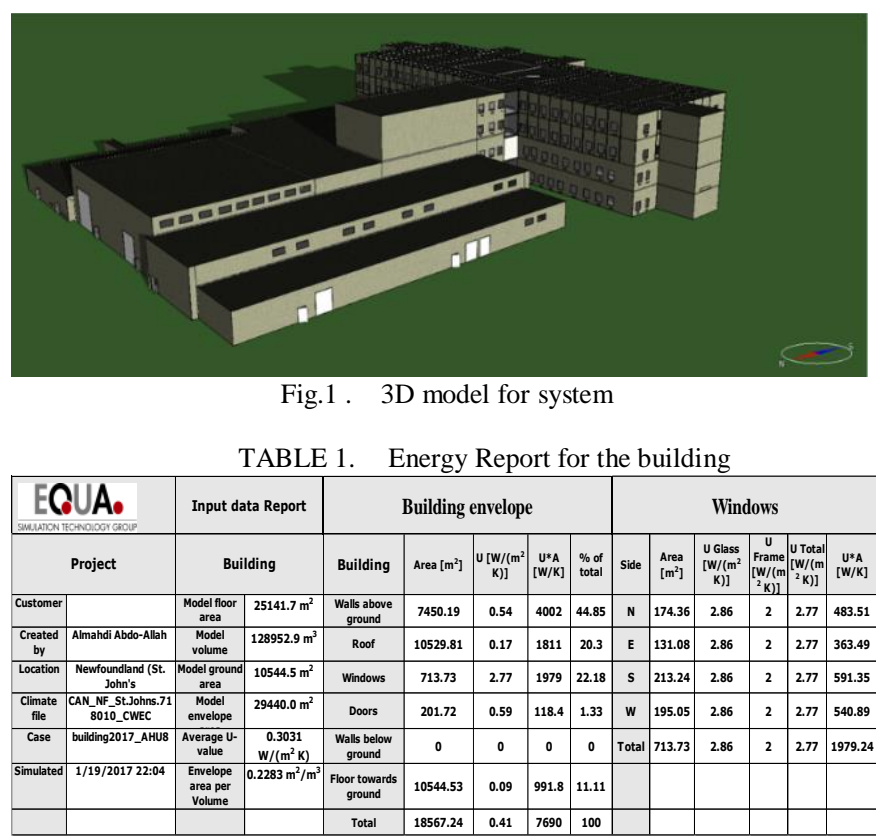

\section{Simulation ToOL}

The Carew building's multifaceted interior climate and energy use is modeled by the IDA-ICE 4.7 simulation tool. This tool can easily model multiple-zone HVAC systems like those existing within the Carew. Through dynamic simulations based on the monitoring and measuring of internal air quality (IAQ), the IDA-ICE 4.7 can gauge desirable thermal comfort levels for the structure. For instance, to maintain individual zonal temperatures, the heat exchanger employs controllers that are set to fixed points through control valve modulation. Figure 2 illustrates how a hot water valve gathers pertinent data on water which has been warmed via direct contact with a heating coil. As shown in the figure, the building's system has only one valve to produce hot water, but the IDA-ICE tool creates four subvalves to allow every air-handling unit its own valve [28, 29]. 


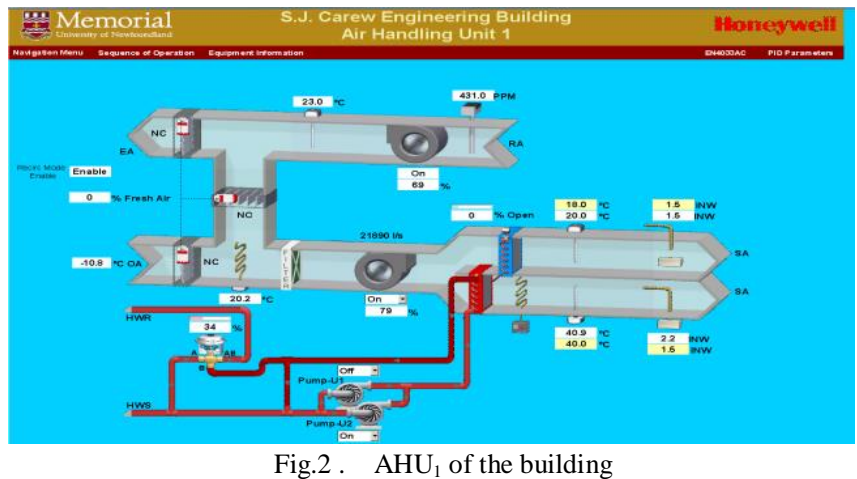

\section{Simulation VALIDATION FOR IDA-ICE}

Two key features that are necessary to forming a viable model are the model's ease in satisfying specifications and the model's accuracy. Figure 3 depicts the Carew building's Jan-Dec/2016 hot water usage as modelled in IDAICE. The figure shows hot water energy consumption exceeding $800,000 \mathrm{kWh}$ per month in winter and nearly $300,000 \mathrm{kWh}$ per month for July and August. Real (i.e., measured) data for the building's annual power consumption shows lower hot water usage in some months compared to others, but the overall consumption levels for both the real and modeled data are nearly the same. Electrical power use data for both the IDA-ICE model and real consumption are shown in Figure 4. The real data is somewhat higher than the simulation data, which could be a result uncontrolled lighting and equipment in the building.

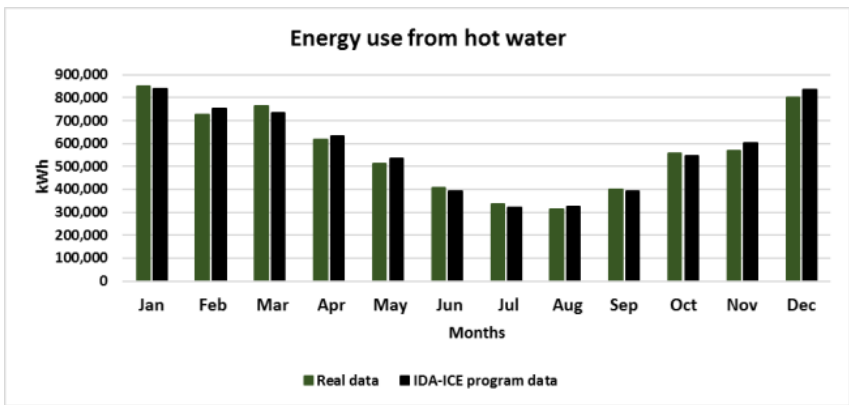

Fig.3 . Energy use from hot water

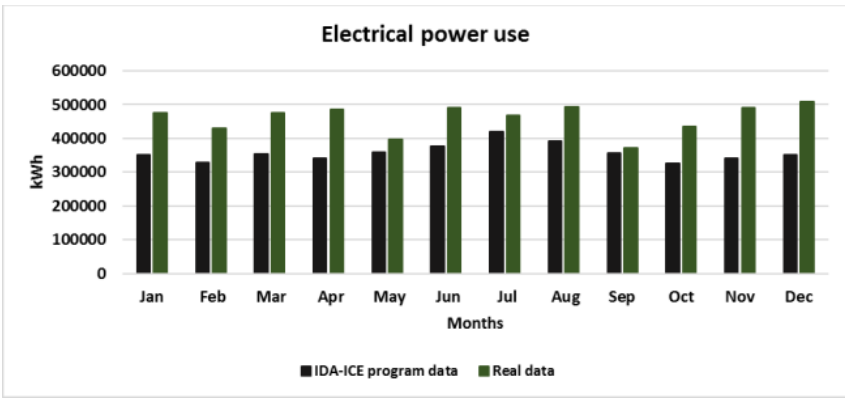

Fig.4 . Electrical power use

\section{SYSTEM IDENTIFICATION}

The present study employed the simulation tool IDAICE 4.7 to model the internal environment and energy performance of the S. J. Carew building on the Memorial University campus, St. John's, Newfoundland. IDA-ICE software can easily simulate \& model HVAC systems that have multi-zonal features. The simulation tool can also measure a range of other important parameters, such as power requirement, thermal comfort levels, and interior air quality (IAQ). To model the building, the identification data must have the zonal inputs and outputs. System identification occurs over three consecutive steps, as listed below [30, 31]:

i. Data collection towards identification of appropriate model.

ii. Choice of most suitable model structure.

iii. Construction of optimal model that satisfies required specifications and provides accurate results.

The main focus, when following through on each of the above steps, should be on choosing and then optimizing a model to reflect the real-life needs of the system. In this study, the Carew building has four AHUs, so the state space model was deemed most appropriate. Moreover, because our data employed for system identification were sourced in the winter (November to April), the chiller were not operational during that time frame. As the Carew building features four AHUs over four floors, there are 12 inputs and 12 outputs (i.e., 3 inputs $[U]$ and 3 outputs $[Y]$ for each AHU). Each AHU inputs are

1. hot water valve for the heating coil/zones radiators

2. supply fan speed

3. fresh air from outdoors

The system controlled outputs for each AHU are

1. Return air temperature (unit is degree Celsius, ${ }^{\circ} \mathrm{C}$ ) for controlling the valve aperture of hot water

2. Static Air Pressure $P_{S}$ (unit is inch in water, INW) in ducts for controlling supply fan speed

3. $\mathrm{CO}_{2}$ levels (unit is parts per million, PPM) for controlling fresh air dampers.

A detailed state space model used for controller design for $\mathrm{AHU}_{1}$ was presented in [29].

\section{CONTROL STRATEGIES}

The simulation results of the fuzzy control methods developed in this research work suggest enhanced comfort levels and energy efficiency across the entire system. The outcome of these improvements would therefore also indicate improved cost efficiencies. Overall, we can assert that fuzzy logic can work with partial truth values along the same lines as humans process ideas and in this way have certain advantages in comparison to traditional controllers, such as:

i. Fuzzy controllers can work with control process models that are imperfect or incomplete (i.e., they do not require mathematical precision).

ii. Employing fuzzy modelling conditions and parameters actually expands the application of successful control strategies due to the flexibility of the model.

iii. We can successfully model non-linear processes, which are applicable to HVAC systems because these systems are nonlinear.

iv. Fuzzy controller systems can perform the function of approximate decision-making and reasoning, just like human thought processes. 
v. In a fuzzy controller, multi-input / multi-output parameter strategies are controllable.

A number of different methods have been successfully used to employ fuzzy logic in a closed-loop control system, but the fuzzy PI controller is currently the most popular approach [32, 33]. In this strategy, fuzzy logic controller inputs and outputs are used to work the actuators, with fuzzy PI controllers serving as incremental controllers. Equation (1) expresses the formulation of a traditional fuzzy PI controller, with the output determined by fuzzy rules [34].

$$
u(k+1)=u(k)+\Delta u(k)
$$

where $k$ indicates sampling instance and $\Delta u(k)$ denotes the controller's incremental change. $K$ was selected as $3 \mathrm{~s}$

For the AHU model, this case study utilizes a traditional fuzzy PI controller. Combining the proportional (P) and integral (I) actions enhances the inherent stability that is characteristic of proportional controllers. When a motor or valve are the actuator, incremental controllers are the appropriate choice. Fuzzy PI controllers are also suitable if the controller output comes mainly from an integrator, as these types of controllers are easily able to mitigate issues such as wind-up and noise.

Figure 5 illustrates how a fuzzy PI controller uses as inputs error and changes of error signals. An additional feature of fuzzy PI controllers is that they are not limited by operational set-points. In control methods that are rule-driven, any discrepancies between measured or set-point values are first discerned to determine whether it is appropriate to use increments or decrements for the control variables. However, in fuzzy logic controllers, non-linear control strategies can be performed by using fuzzy logic for actual applications, as follows [35]:

a) In Fuzzification, crisp data is turned into fuzzy data, which are also known as membership functions (MFs).

b) MFs are then included as part of the control rules to find the requested fuzzy output, a process which is termed fuzzy inference.

c) Finally, in the defuzzification step, several different approaches are employed in order, firstly, to incorporate all relevant outputs, secondly, to position them as in a table format, and thirdly, to find the output in a look-up table that matches the current input in the desired application.

Figure 5 shows the fuzzy controller being designated to control $\mathrm{CO}_{2}$ levels, static air pressure, and zonal temperatures. As illustrated in the figure, the fuzzy controller is fed error signals and modifications, with the fuzzy controller outputs used as system inputs. The resulting outputs are then forwarded to the fuzzy controller, forming a closed-loop control system.

Figure 6 depicts a fuzzy logic design in Matlab fuzzy logic toolbox according to system specifications (e.g., add/remove input/output or select fuzzy inference operations could be done in Matlab toolbox).

SFLC of the system have 24 inputs as following: 1) 8 inputs are temperature differences $(\Delta T)$ and the ratio for the difference $(d \Delta T)$ of AHUs, 2) 8 inputs are static air pressure
$\mathrm{P}_{S}$ differences $\left(\Delta P_{S}\right)$ and the ratio for the difference $\left(d \Delta P_{S}\right)$, and 3) 8 inputs are differences in $\mathrm{CO}_{2}$ Levels $\left(\triangle C \mathrm{CO}_{2}\right)$ and the ratio for the difference $\left(d \Delta \mathrm{CO}_{2}\right)$. There are 12 outputs of the SFLC, each AHU has three (fresh air, air flow and hot water).

The values are introduced as gains to the system to move system responses towards a stability state. As a means to increase output gains, PI controller tuning can be used.

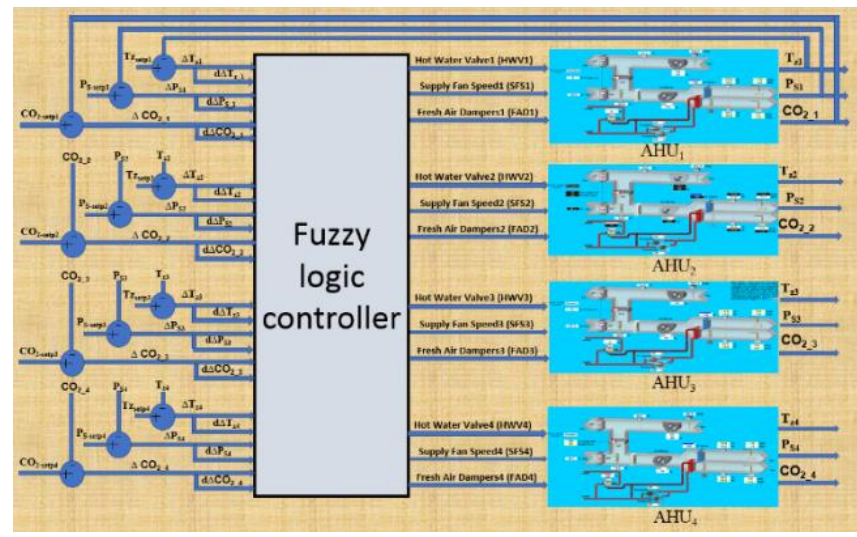

Fig.5 . The SFLC with four AHUs.

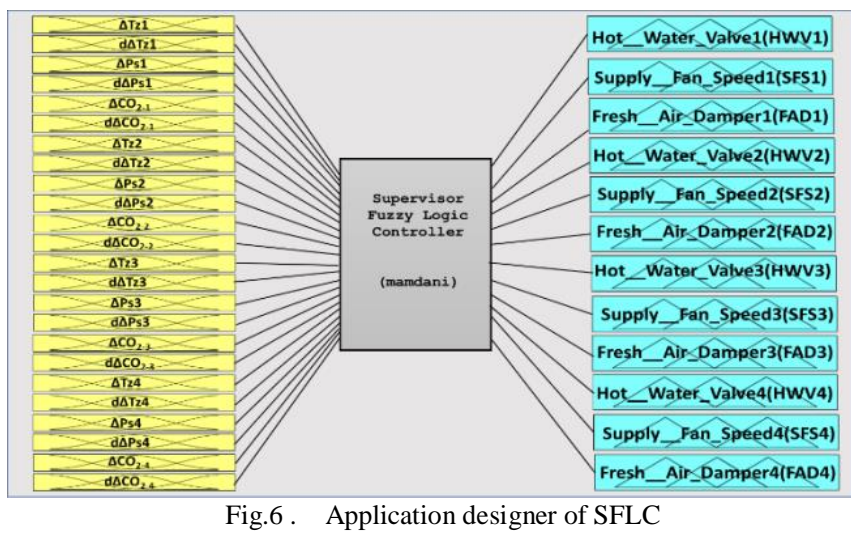

\section{A. Fuzzy Membership Function}

The MFs editor is used to separate the fuzzy toolbox that is in the form defined by all membership variables for MFs. The final factors are assigned to the variable inputs and output variables as follows:

\section{SFLC input variables}

The control system has 6 inputs from each AHU. Three for difference between setpoints and current values and three inputs are the ratio for response differences. The following data show inputs from $\mathrm{AHU}_{1}$. Also, Tables 2 and 3 illustrate the details of all controller inputs.

a. Temperature Differences of $A H U_{I}\left(\Delta T_{z l}\right)$. Zone temperature of return air as recorded by an electronic sensor as shown in Fig. 2 that Eq. (2) expresses differences between setpoint $\left(T_{\text {setp } 1}\right)$ and current zone temperature $\left(T_{z l}\right)$ for time $(\mathrm{k})$. Figure 7 shows the five MFs of (V-High, High, Optimal, Low, and V-Low). Table 2 illustrate the details of this MFs.

$$
\Delta T_{z 1}(k)=T_{\text {setp } 1}(k)-T_{z 1}(k)
$$




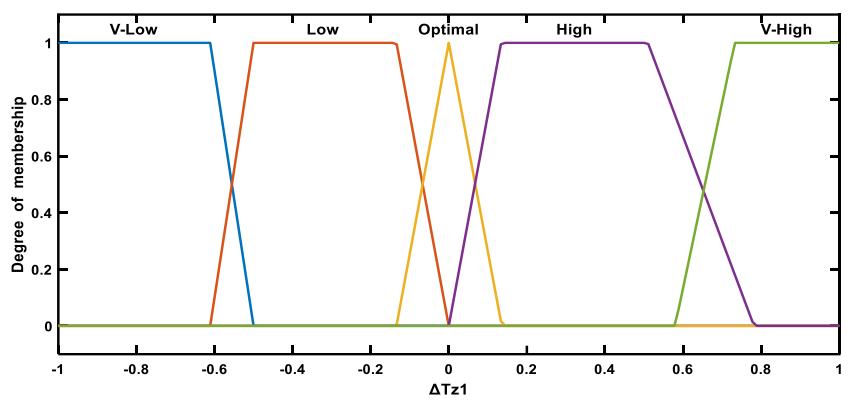

Fig.7 MFs differences between setpoint $\left(T_{\text {setpl }}\right)$ and current zone temperature $\left(T_{z 1}\right)$

b. Change in $\Delta T_{z I}$ in $A H U_{1}\left(d \Delta T_{z l}\right)$. The variables for the error input in temperature changes are set by observing the difference ratio between current and actual temperature error values and the sampling time $(\Delta t)$, as shown in Eq. (3). The building's real system gives a system sampling time of three seconds (Honeywell Offices and Department of Facilities Management and at Memorial University). Figure 8 and Table 3 illustrate that three MFs used to define error variable changes: Positive $(P)$, Negative $(N)$, and Zero $(Z)$

$$
\left(d \Delta T_{z 1}\right)=\left(\Delta T_{z 1}(k)-\Delta T_{z 1}(k-1)\right) / \Delta t \quad\left({ }^{\circ} C / s\right)
$$

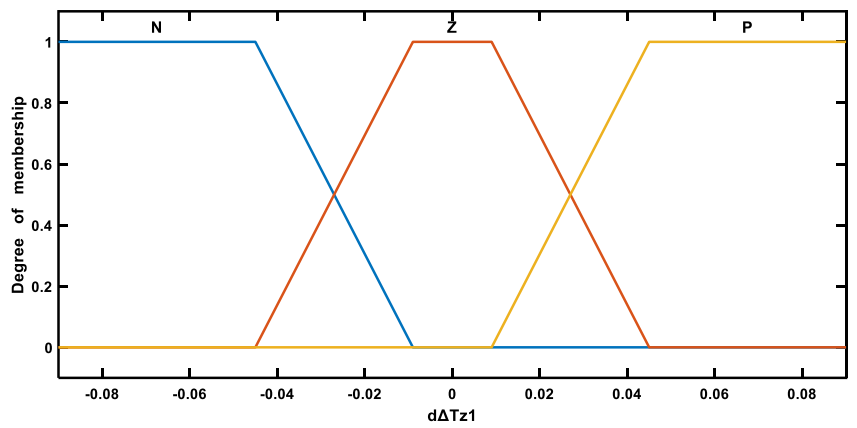

Fig.8 MFs ratio between current and actual temperature

c. Static Air Pressure Differences of $A H U_{1}\left(P_{S I}\right)$. Figure 2 illustrates changes in present duct $P_{S}$, these differences were noted by sensors located in both coldand hot-deck ducts. As can be seen, the static pressure $\left(P_{S \text {-setpl }}\right)$ setpoints occur for time $(\mathrm{k})$, given in Eq. (4). Figure 9 and Table 2 present five MFs of (V-High, High, Optimal, Low, and V-Low).

$$
\Delta P_{S 1}(k)=\Delta P_{S-\operatorname{setp} 1}-P_{S 1}(k) \quad(I N W)
$$

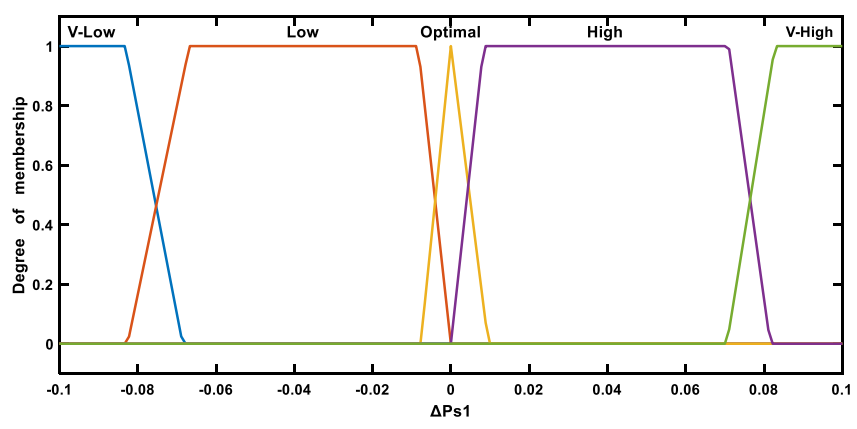

Fig.9. MFs of Static Air Pressure Differences

d. Change in $\Delta P_{S I}\left(d \Delta P_{S I}\right)$ in $A H U_{l}$. As expressed in Eq. (5), All changes of the $\left(P_{S}\right)$ error input variables are made with ratios for the differences between current and actual $\left(P_{S}\right)$ values depending on the sampling time $(\Delta t)$. Figure 10 shows three MFs that show changes in the displayed error variables Positive $(P)$, Negative $(N)$, and Zero $(Z)$.

$d \Delta P_{S 1}(k)=\left(\Delta \mathrm{P}_{S 1}(k)-\Delta \mathrm{P}_{S 1}(k-1)\right) \Delta t \quad(I N W / s)$

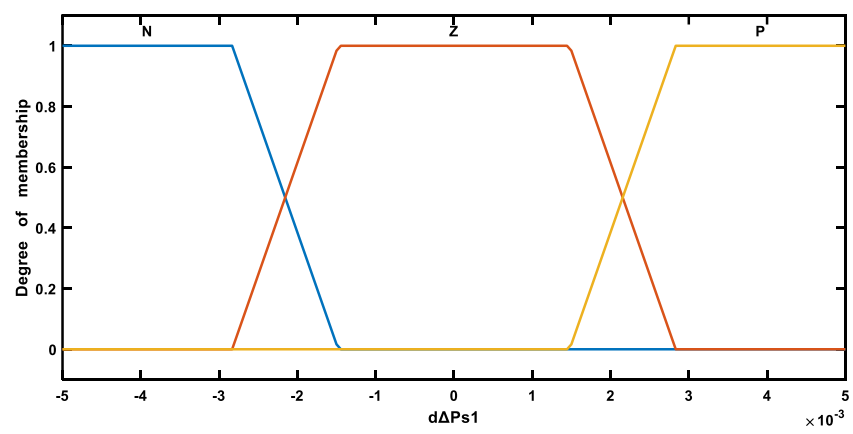

Fig.10 . MFs of ratios for the differences between current and actual $\left(P_{S}\right)$ values

e. Differences in $\mathrm{CO}_{2}$ Levels in $\mathrm{AHU}_{1}\left(\triangle \mathrm{CO}_{2-1}\right)$. As shown in Figure 2, this is the difference between the current $\mathrm{CO}_{2-1}$ level in the return air from the sensor in the $\mathrm{AHU}_{1}$ return duct and the $\mathrm{CO}_{2}$ level of setpoint $\mathrm{CO}_{2}$ setp1, as recorded at time (k) and expressed by Eq. (6). The 5 MFs of (V-High, High, Optimal, Low, and VLow) are shown in Figure 11.

$$
\Delta \mathrm{CO}_{2-1}(k)=\mathrm{CO}_{2-\operatorname{setp} 1}-\mathrm{CO}_{2-1}(k) \quad(P P M)
$$

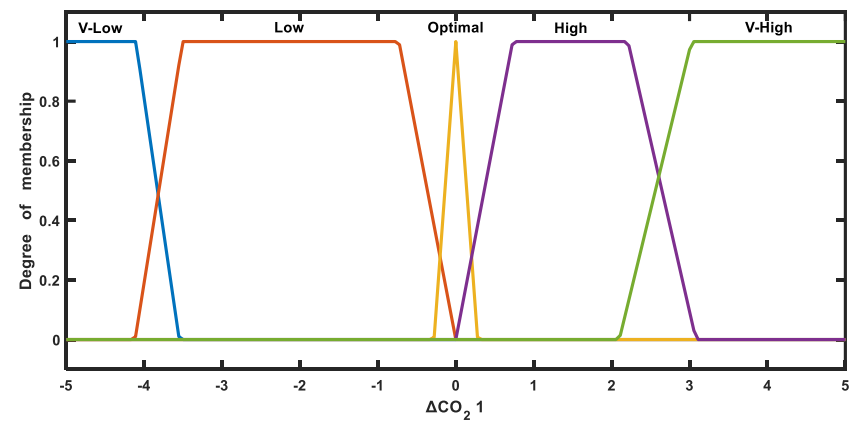

Fig.11 . Difference between the current and setpoint of $\mathrm{CO}_{2-1}$ level

f. Change in $\Delta \mathrm{CO}_{2-1}\left(d \Delta C \mathrm{O}_{2-1}\right)$. As indicated in Eq. (7), the input variable $\mathrm{CO}_{2}$ error changes can be formed by observing the difference ratio between the current and previous $\mathrm{CO}_{2}$ error values as a function of the sampling time $(\Delta t)$. Figure 12 show the three MFs error variable changes as sets labelled Positive $(P)$, Negative $(N)$, and Zero $(Z)$.

$$
d \Delta C O_{2-1}(k)=\left(\Delta C O_{2-1}(k)-\Delta C O_{2-1}(k-1)\right) \Delta t
$$$$
(P P M / s)
$$

Table 2 and Table 3 lists all limits of MFs used in Matlab fuzzy logic toolbox for all AHUs. 


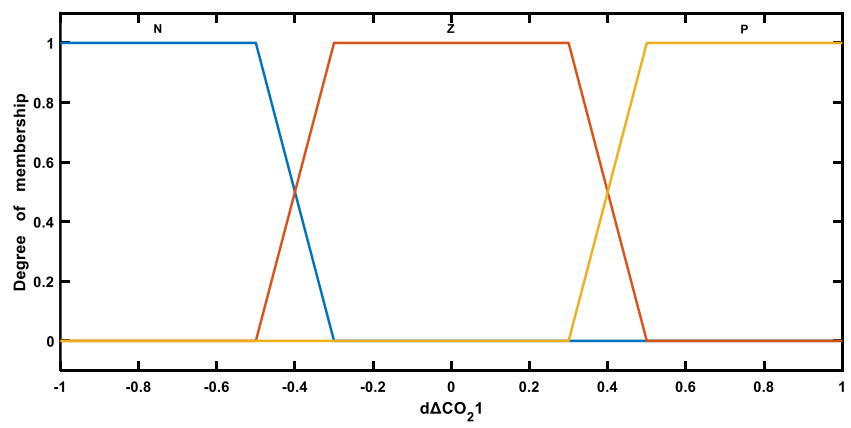

Fig.12 . Difference ratio between current and previous $\mathrm{CO}_{2}$ error values

TABLE 2. Difference between setpoints and current values

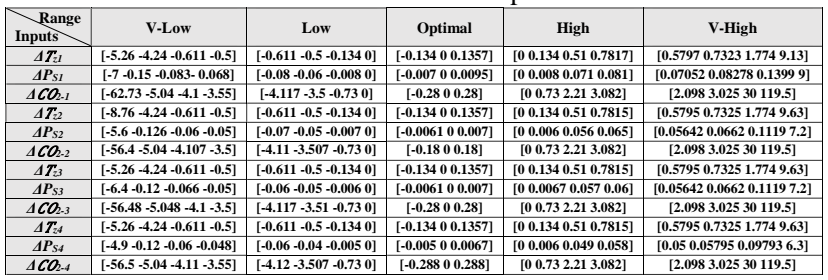

TABLE 3. Ratio between the current and previous values

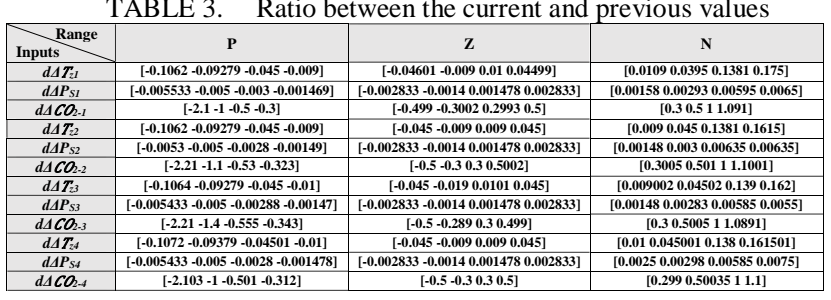

\section{Output Variables.}

The inlet of all ventilation units (hot water, fan speed and fresh air) acts as an SFLC output. This means that SFLC has twelve output. Values are entered as a gain in the system to introduce system reactions into a steady state. To increase the output gain, the tuning of a PI controller can be used, as described the outputs of the first $\mathrm{AHU}_{1}$ in the following subsections [29]. Also, the table 4 illustrate all the details of MFs (Close-Fast, Close, NoChange, Open and Open-Fast) and the related operation percentages of hot water valve's, fan speed and fresh air dampers of whole system.

a. Aperture on Hot Water Valve of $A H U_{l}\left(H W V_{l}\right)$. The

$5 \mathrm{MFs}$ indicates the output of the process controller to open and close the hot water valve to set the temperature range of the zone $\left(T_{\text {setpl }}\right)$. Figure 13 depicts MFs using MATLAB/Fig.

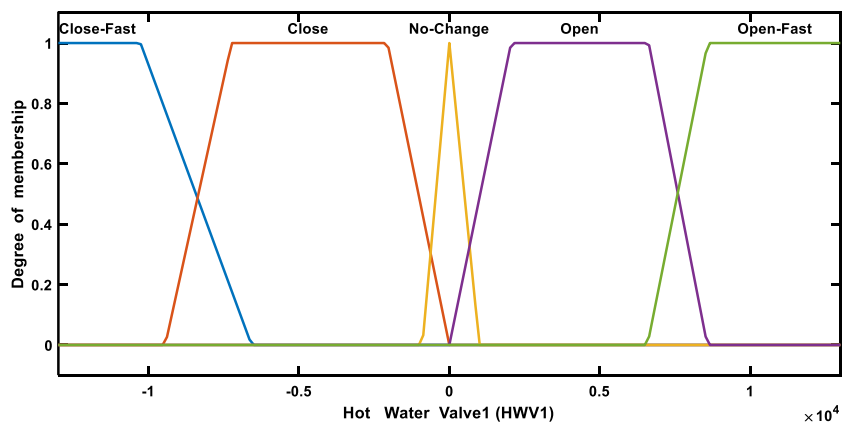

Fig.13. MFs of the first output of SFLC b. Supply Fan Speed of $A H U_{1}\left(S F S_{1}\right)$. The second output of the SFLC is the speed control of the supply fan to reach the static air pressure setpoint $\left(P_{S \text {-setp }}\right)$ inside ducts. Figure 14 shows the five MFs for this process.

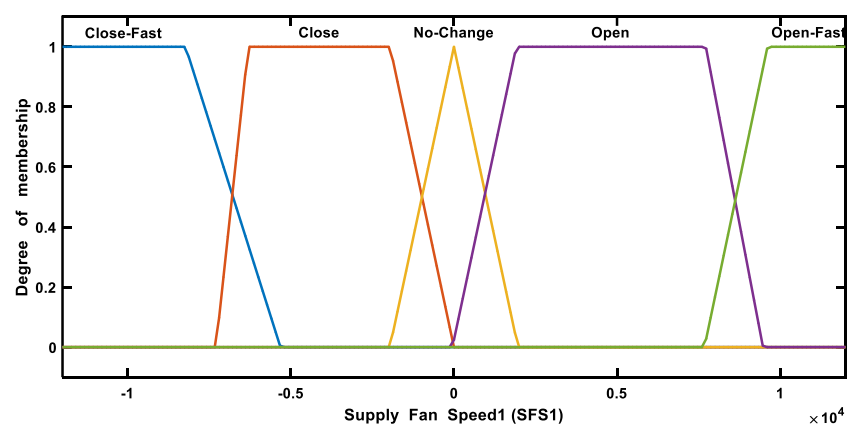

Fig.14. The second output of the SFLC

c. Fresh Air Dampers Position of $A H U_{I}\left(F A D_{l}\right)$. Five MFs were used for the controller output to open and close the position of the fresh air dampers to

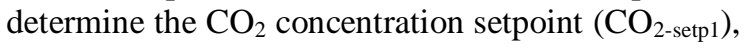
Figure 15 shows that. Table 4 provides list of limits of output MFs of all AHUs.

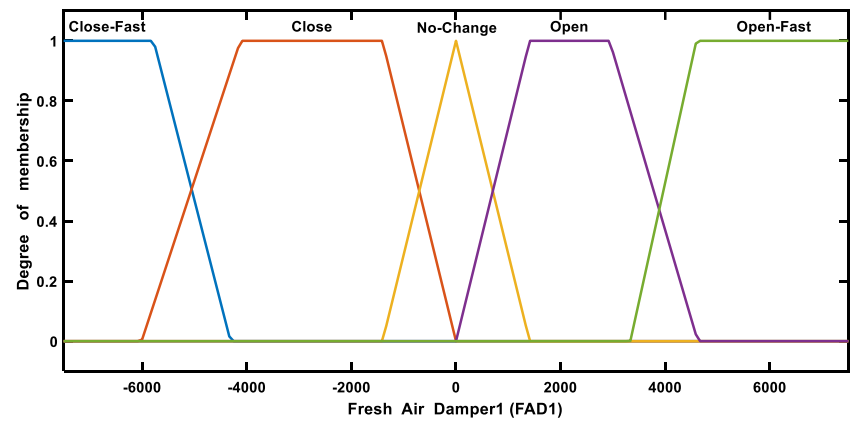

Fig. 15. The third output of the SFLC

TABLE 4. All the outputs of SFLC

\begin{tabular}{|c|c|c|c|c|c|}
\hline Corre & & & & 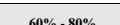 & 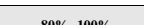 \\
\hline & & & & & \\
\hline $\begin{array}{l}\text { Rang } \\
\text { utputs }\end{array}$ & Close-Fast & Close & No-Change & Open & Open-Fast \\
\hline$H W V_{t}$ & {$[-17160-13000-10270-6578]$} & {$[-9447-7241-20540]$} & {$[-8950998]$} & [02054 6630 8576] & [6588 8590 13280 13340] \\
\hline$S F S_{t}$ & {$[-14020$ - $12170-8227-5319]$} & {$[-7296-63077-19580]$} & {$[-1963 \mathrm{C}$} & [0 1911 727239475] & 776809612 \\
\hline$F A D_{t}$ & {$[-7823-7545-5779-4310]$} & {$[-6010-4121-14050]$} & {$[-140401407]$} & [0 1408 2936 4622] & {$[3332459575157988]$} \\
\hline$H W V_{2}$ & {$[-15840$ - $12000-94733-6072]$} & {$[-8717-6684-189600]$} & {$[-8260921]$} & {$[018966121207913]$} & {$[608179291226012310]$} \\
\hline $\mathrm{SFS}_{2}$ & {$[-8768-7605-5138-3323]$} & {$[-4563-3938-12230]$} & {$\left[\begin{array}{llll}-1227 & 01227]\end{array}\right.$} & {$[0119548275925]$} & {$[4800600875157583]$} \\
\hline$\overline{F A I}$ & {$[-11460-11060-8476-6322]$} & {$[-8814-6044-20620]$} & {$[-2059020665]$} & {$[0206643076778]$} & {$\left[\begin{array}{l}48866738 \\
11020\end{array} 11720\right]$} \\
\hline $\mathrm{HWV}_{3}$ & {$[-11090-8400-6631-4249]$} & {$[-6102-4679-13270]$} & {$[.5780645]$} & [0 132742845539$]$ & [4257 5549858586617$]$ \\
\hline $\mathrm{SFS}_{3}$ & {$[-7010-6083-4110-2659]$} & {$[-3652-3150 .-9790]$} & $810981]$ & {$[0955.838624735]$} & {$[384048056014$ 6065] } \\
\hline$F A I$ & {$[-9379-9053$.} & {$[-7211$} & [-168 & 1016 & [3998 551490179587$]$ \\
\hline$H W V_{s}$ & {$[-11220-8500-6707-4301]$} & {$[-6172-4735-13430]$} & {$[-5850652]$} & [0 134343355604$]$ & {$[43075616868668720]$} \\
\hline$S F S$ & {$[-31540-27410-18520-11960$} & {$[-16450-14180-44060]$} & & {$\left[\begin{array}{l}042981736021330] \\
\end{array}\right.$} & {$[17280216202705027990]$} \\
\hline$F A D_{4}$ & {$[-17600-17010-13020-9709]$} & {$[-13550-92877-31660]$} & 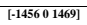 & [0 3177661610400$]$ & {$\left[\begin{array}{l}7505 \\
10330\end{array} 1693018020\right]$} \\
\hline
\end{tabular}

\section{B. Fuzzy Rules}

In systems that operate using fuzzy inference, the output variables are controlled by fuzzy rules, which essentially are IF-THEN rules that contain both a condition and a conclusion. Fuzzy membership functions can alter input errors $\left(\triangle T z, \triangle P S, \Delta C O_{2}\right)$ as well as error changes $(d \Delta T z$, $d \triangle P S, d \Delta \mathrm{CO}_{2}$ ) in accordance with their appropriate fuzzy values. Additionally, for each output investigated in this paper (e.g., hot water valve, fan speed and damper position), fuzzy rules provide the control action for values of error and error changes [36-38]. Note that because each control signal output has $5 \times 3$ i.e. 15 rules. Table 5 illustrate the rules between first and second input $\left(\Delta T z_{1}\right.$ and $\left.d \Delta T z_{1}\right)$ of the controller as the fuzzy default rule, there are three inputs in 
each AHU and four AHUs for the system, that mean the SFL controller has $(15 \times 3 \times 4) 180$ rules. Also, The SFLC can control aspects of energy saving that better the performance of the heating and cooling system of building, taking into account the needs of each floor, for that there is extra rules between floors.

TABLE 5. The rules between first and second input of the controller

\begin{tabular}{|c|c|c|c|c|c|}
\hline$\frac{\Delta \text { inputs }}{d \Delta \text { inputs }}$ & V-Low & Low & Optimal & High & V-High \\
\hline $\mathbf{N}$ & Open-Fast & Open-Fast & Open & No-Change & Close \\
\hline $\mathbf{Z}$ & Open-Fast & Open & No-Change & Close & Close-Fast \\
\hline $\mathbf{P}$ & Open & No-Change & Close & Close-Fast & Close-Fast \\
\hline
\end{tabular}

\section{Defuzzification}

Defuzzification changes fuzzy output variables into crisp variables in order to meet control objectives. The defuzzification step is used in hardware applications where crisp data are exchanged and defuzzified output is deemed the best solution. The underlying mechanisms for this approach are the maxima strategy and the centroid strategy. The maxima approach actively seeks the highest pack, whereas the centroid approach seeks to find the balance point. In our case study of the S. J. Carew building, the centroid method is used.

Figure 16 shows the control surface with the applied MFs. Error values for zonal temperatures along with change of error values based on fuzzy rules have been used. The control output values derive from a range of input combinations in hot water valve functions.

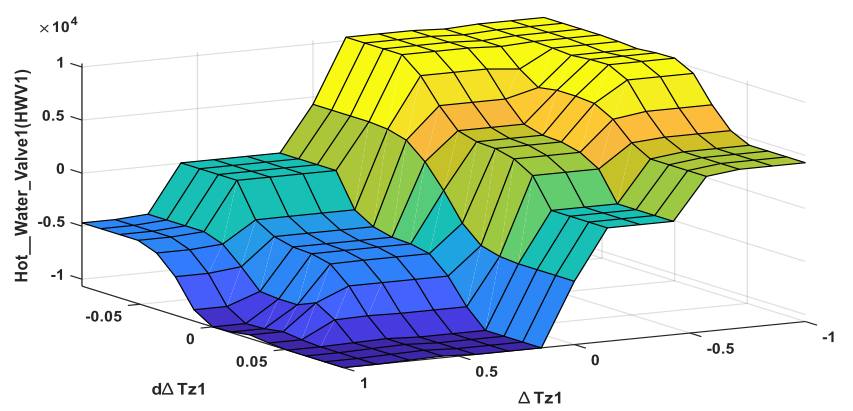

Fig.16. Control surface of $\Delta T_{z I}$ and $d \Delta T_{z I}$ based on fuzzy rules

In Figure 17, the control surface employed to implement static air pressure error value MFs and fuzzy ruleimplemented change of error values is illustrated. In this case, the control output values derive from a range of input combinations for moderating supply fan speed as a means to determine the ducts' static air pressure set-points.

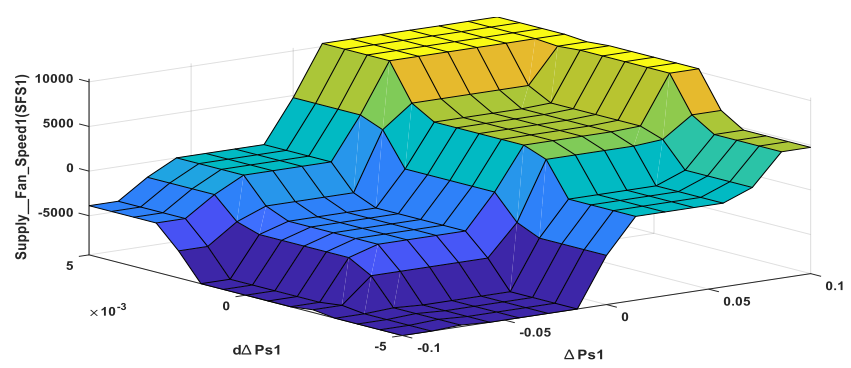

Fig.17 . Control surface of $\Delta P s_{1}$ and $d \Delta P s_{1}$ based on fuzzy rules
The control surface for values of error and changes of error in MFs measuring $\mathrm{CO}_{2}$ levels is depicted in Figure 18. As shown, fuzzy rules have been used to control output values in order to determine the $\mathrm{CO}_{2}$ set-point which is most appropriate.

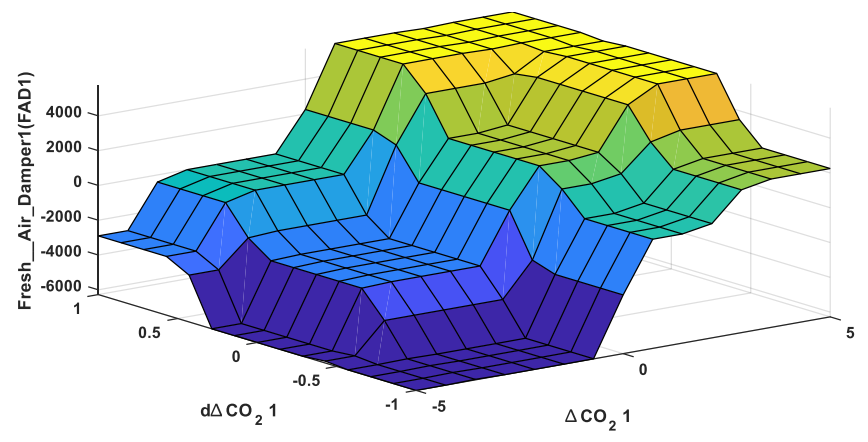

Fig.18 . Control surface of $\triangle C \mathrm{CO}_{2-1}$ and $d \triangle C \mathrm{CO}_{2-1}$ based on fuzzy rules

For the extra rules between floors, the Figure 19 shows the control surface between second and third floor temperature differences for saving energy and better the performance of hot water valve of $\mathrm{AHU}_{2}(H W V 2)$.

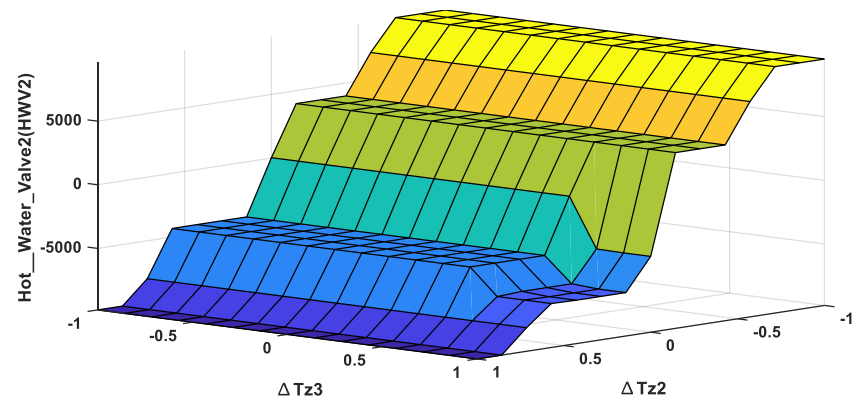

Fig.19. Control surface of $\Delta T z_{2}$ and $\Delta T z_{3}$ based on fuzzy rules

In Figure 20 shows the control surface between second and third floor Static Air Pressure Differences for saving energy and better the performance of supply fan speed of $\mathrm{AHU}_{2}$ (SFS2).

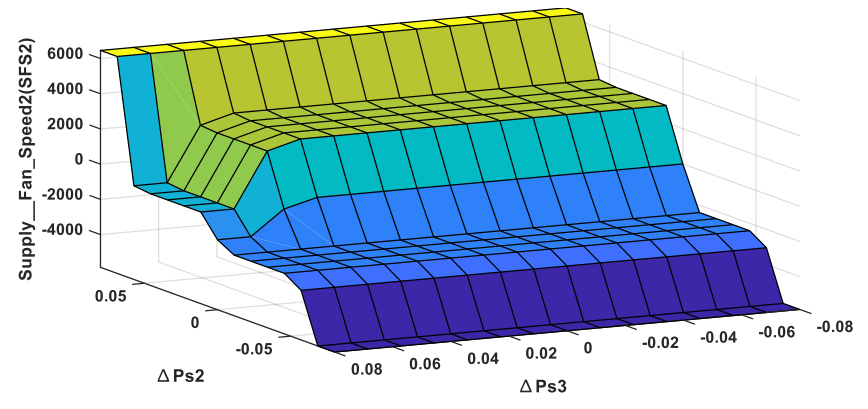

Fig.20 . Control surface of $\Delta P s_{2}$ and $\triangle P s_{3}$ based on fuzzy rules

\section{Simulation AND RESUlTS}

In this section the simulation results and the Simulink model are presented. Figure 21 shows a block diagram for state space models of a whole building (four AHUs), supervisor fuzzy logic controller and all setpoints using MATLAB / Simulink. There are four state space models, each AHU has 
one with 3 inputs and 3 outputs, the advantage of separate the system to four is decrease the rules of the controller. In
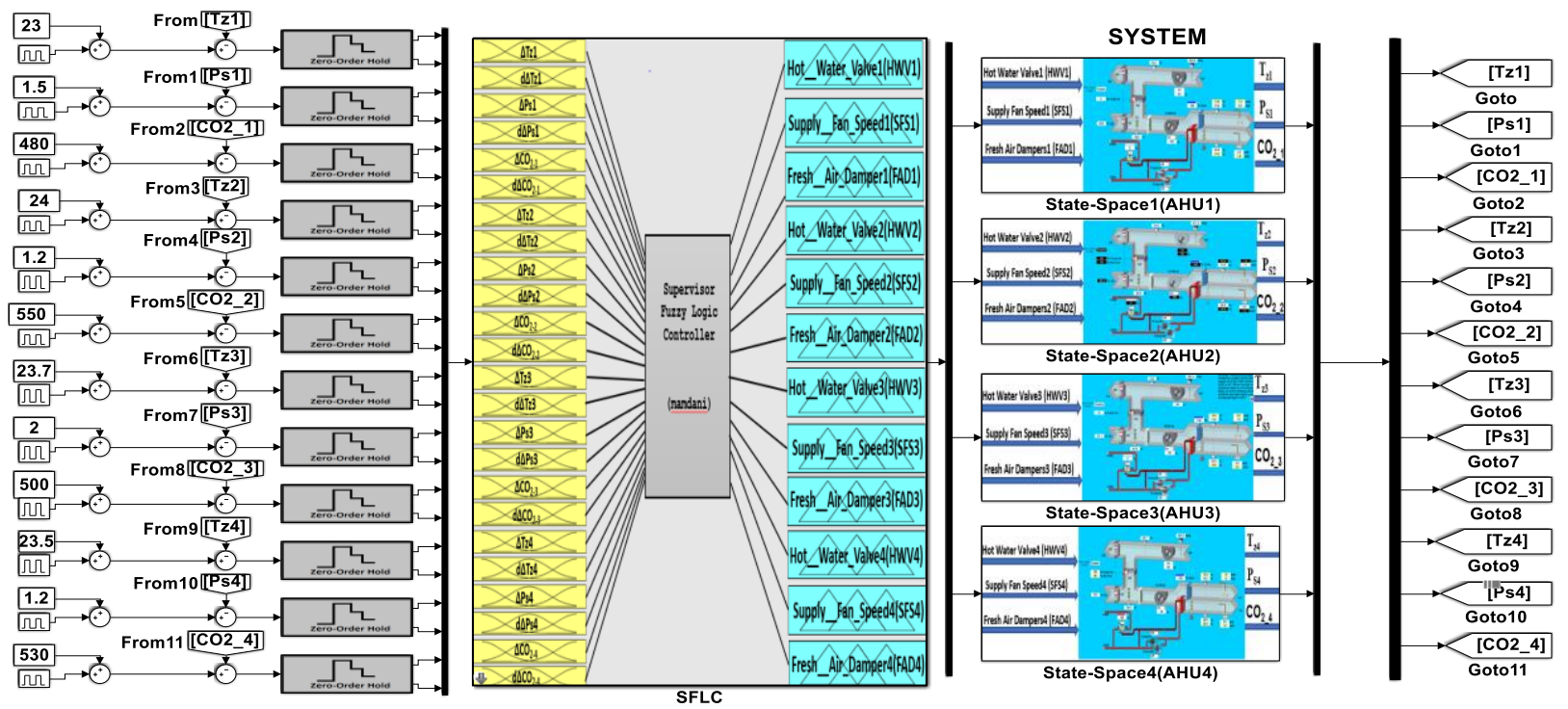

Fig.21 . Block diagram for state space models of whole system with SFLC

addition, the sampling time was selected as 3 seconds of the control action the same as that for the real system [29]. Also, the initial conditions and setpoints are selected for state space model of temperatures, air pressures, and $\mathrm{CO}_{2}$ levels of $\mathrm{AHUs}$ of the system as following:

i. $22.46{ }^{\circ} \mathrm{C}$ for temperature, $1.013 \mathrm{INW}$ for air pressure, and $471 \mathrm{PPM}$ for $\mathrm{CO}_{2}$ levels of the $\mathrm{AHU}_{1}$ initial conditions. Furthermore, the real system's indoor air quality setpoints are a zone temperature of $23{ }^{\circ} \mathrm{C}$, air pressure of $1.5 \mathrm{INW}$, and a $\mathrm{CO}_{2}$ level of 480 PPM.

ii. Initial conditions of $\mathrm{AHU}_{2}$ it was $20.29{ }^{\circ} \mathrm{C}$ for temperature, 1.11 INW for static air pressure, and 502 PPM for $\mathrm{CO}_{2}$ levels. Setpoints are $24{ }^{\circ} \mathrm{C}, 1.2 \mathrm{INW}$, and $550 \mathrm{PPM}$ of zone temperature, air pressure and $\mathrm{CO}_{2}$ level, respectively.

iii. For the $\mathrm{AHU}_{3}$ the initial conditions were $22.31{ }^{\circ} \mathrm{C}$ for temperature, $1.39 \mathrm{INW}$ for static air pressure, and 469 PPM for $\mathrm{CO}_{2}$ levels, the setpoints $23.7^{\circ} \mathrm{C}, 2 \mathrm{INW}$, and $500 \mathrm{PPM}$ of zone temperature, air pressure and $\mathrm{CO}_{2}$ level, respectively.

iv. $\mathrm{AHU}_{4}$ has initial condition of temperature $21.3^{\circ} \mathrm{C}$, static air pressure $1.01 \mathrm{INW}$, and $\mathrm{CO}_{2}$ levels 486 PPM. Setpoints are $23.5{ }^{\circ} \mathrm{C}, 1.2 \mathrm{INW}$, and $530 \mathrm{PPM}$ of zone temperature, air pressure and $\mathrm{CO}_{2}$ level, respectively.

SFLC control characters receive both errors and changes. System input control signals can be changed, including hot water, fresh air, and airflow gains to reach the reference points. Figure 22 shows the first of the system's output responses of each AHU that demonstrate the system's stability. Zones temperature $\left(\mathrm{T}_{\mathrm{z} 1}, \mathrm{~T}_{\mathrm{z} 2}, \mathrm{~T}_{\mathrm{z} 3}\right.$ and $\left.\mathrm{T}_{\mathrm{z} 4}\right)$ achieves setpoints of $23{ }^{\circ} \mathrm{C}, 24^{\circ} \mathrm{C}, 23.7^{\circ} \mathrm{C}$ and $23.5^{\circ} \mathrm{C}$ at good rise time and there is a small overshoot of some responses. Also, the setpoints of the system were changed to see the action of the controller, the figure shows good responses with this change.

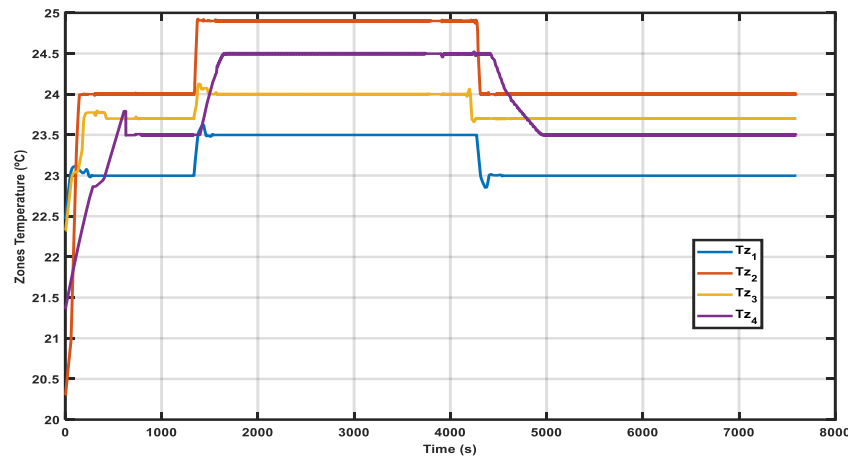

Fig.22 . Zones temperature responses

Figure 23 depicts the second responses of static air pressure of AHUs $\left(\mathrm{Ps}_{1}, \mathrm{Ps}_{2}, \mathrm{Ps}_{3}\right.$ and $\left.\mathrm{Ps}_{4}\right)$, with perfect rise time and some small overshoots of the responses. With the changing of the references of the system for period of time the responses have no study state error.

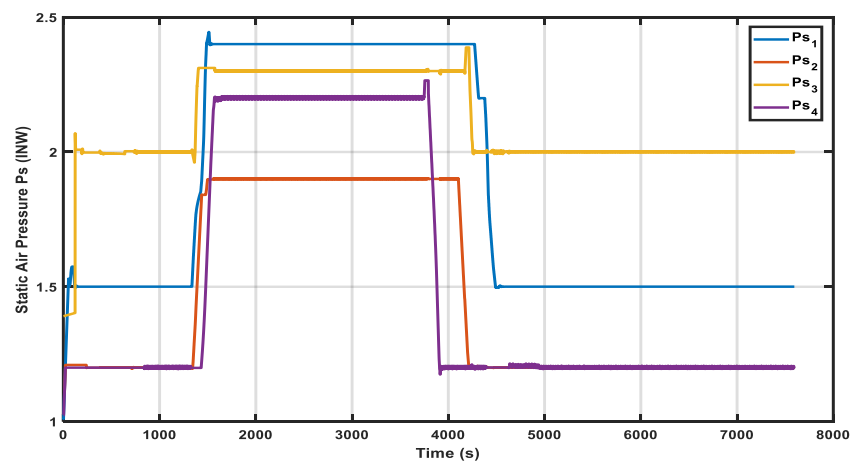

Fig.23 . Responses of static air pressure of AHUs

Figure 24 shows the $\mathrm{CO}_{2}$ level responses of AHUs $\left(\mathrm{CO}_{2-1}\right.$, $\mathrm{CO}_{2-2}, \mathrm{CO}_{2-3}$ and $\mathrm{CO}_{2-4}$ ), achieving the setpoints of $\mathrm{CO}_{2}$ level with good rise time and small overshoot of some responses. 
As before the setpoints were change in period of time, the next figure shows that.

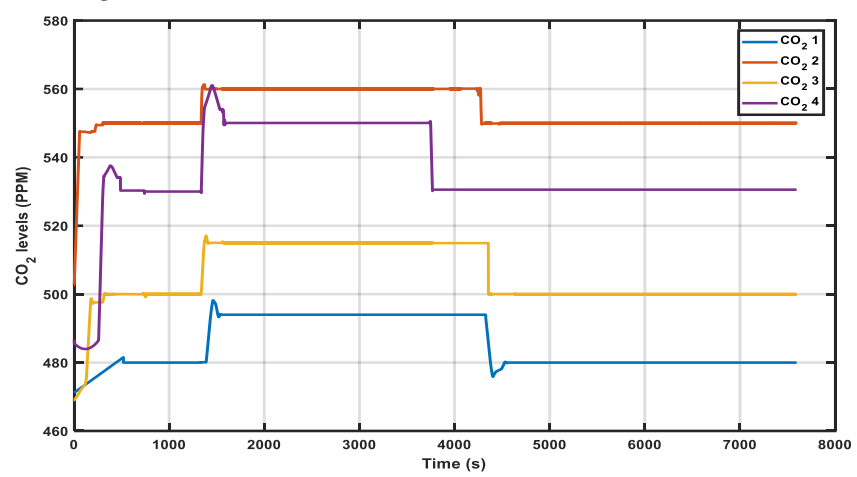

Fig.24. $\mathrm{CO}_{2}$ level responses of AHUs

\section{CONCLUSIONS}

The simulation results covered the proposed HVAC model, which reflects its capability in maintaining comfort conditions. The S.J Carew building control system was simulated in MATLAB 2018a. The building's AHUs were modelled with the MATLAB System Identification Toolbox with real data and IDE-ICE results available to determine input and output system parameters. The designed supervisor fuzzy logic controller modulates the AHUs input (fresh air distributing air flow and hot water for each AHU) to achieve comfort level in the building. Modelling building each floor as a separate block results in four spatial models that offers advantage that the rules of the supervisor controller are reduced to 180 . The results show that the performance of fuzzy controller was better compared to traditional algorithms and current controller used to control HVAC system. In addition, the SFLC algorithm responded systematically to all laboratory conditions and was able to handle a variety of parameters, including response time, steadying errors, and overshoot. By adding additional rules between the entry steps, the SFLC can control energy saving features and results in an improved performance in the heating and cooling of buildings.

\section{Data availability}

All data are available with us.

\section{Conflicts of Interest}

The authors declare that they have no conflicts of interest.

\section{Acknowledgments}

This work is funded by the Ministry of Higher Education of Libyan Government, which is managed by CBIE in Canada. Also, the authors thank the Honeywell Office and Department of Facilities Management at Memorial University for providing them with structure details of the the S. J. Carew building and access to Honeywell software of HVAC system.

\section{References}

[1]. A. Abdo-Allah,T. Iqbal, and K. Pope, "Modeling, analysis, and state feedback control design of a multi-zone HVAC system," Journal of Energy, vol. 2018, Article ID 4303580, 11 pages, 2018.

[2]. Abel, Enno, Per-Erik Nilsson, Lars Ekberg, Per Fahlén, Lennart Jagemar, Roger Clark, Ole Fanger et al. “Achieving the desired indoor climate-energy efficiency aspects of system design," Studentlitteratur, 2003.

[3]. Awbi H. Ventilation of buildings, Spon Press; 2003.

[4]. Goodfellow, Howard D. Industrial ventilation design guidebook Elsevier, 2001.

[5]. American Society of Heating Refrigerating and Air-Conditioning Engineers, ASHRAE handbook, fundamentals, 2009.

[6]. S. Huang and R. M. Nelson, "Rule development and adjustment strategies of a fuzzy logic controller for an hvac system: part one analysis," ASHRAE Transactions-American Society of Heating Refrigerating Air Conditioning Engine, vol. 100, no. 1, pp. 841-850, 1994.

[7]. T. Tobi and T. Hanafusa, "A practical application of fuzzy control for an air-conditioning system," International Journal of Approximate Reasoning, vol. 5, no. 3, pp. 331-348, 1991.

[8]. J. Liang and R. Du, "Thermal comfort control based on neural network for HVAC application," in Proceedings of the IEEE Conference on Control Applications (CCA '05), pp. 819-824, Toronto, Canada, 2005.

[9]. A. I. Dounis, M. J. Santamouris, and C. C. Lefas, "Implementation of artificial intelligence techniques in thermal comfort control for passive solar buildings," Energy Conversion and Management, vol. 33, no. 3, pp. 175-182, 1992.

[10]. C. V. Altrock, H.-O. Arend, B. Krause, C. Steffens, and E. BehrensR"ommler, "Adaptive fuzzy control applied to home heating system," Fuzzy Sets and Systems, vol. 61, no. 1, pp. 29-35, 1994.

[11]. M. Trobec Lah, B. Zupan cǐc, J. Peternelj, and A. Krainer, "Daylight illuminance control with fuzzy logic," Solar Energy, vol. 80, no. 3, pp. 307-321, 2006.

[12]. M. T. Lah, B. Zupaňcǐc, and A. Krainer, "Fuzzy control for the illumination and temperature comfort in a test chamber," Building and Environment, vol. 40, no. 12, pp. 1626-1637, 2005.

[13]. Honeywell. 1989. Engineering Manual of Automatic Control for Commercial Buildings: Heating, Ventilating, Air Conditioning. Minneapolis, MN: Honeywell Plaze.

[14]. Levenhagen, J.I., and D.H. Spethmann. 1993. HVAC Controls and Systems. New York. McGraw-Hill, Inc.

[15]. Wang, S.W., and X.Q. Jin. 2000. "Model-based optimal control of VAV air-conditioning system using genetic algorithm," Building and Environment 35(6):471-87.

[16]. Zaheer-uddin, M., and G.R. Zheng. 2000. "Optimal control of timescheduled heating, ventilating and air conditioning processes in building," Energy Conversion and Management 41(1):49-60.

[17]. Hordeski, M.F. 2001. HVAC Control in the New Millennium. Lilburn, GA: The Fairmont Press, Inc.

[18]. Haines, R.W., and D.C. Hittle. 2003. Control Systems for Heating, Ventilating and Air Conditioning (Sixth Edition). Boston: Kluwer Academic Publishers.

[19]. Nassif, N., S. Kajl, and R. Sabourin. 2005. "Optimization of HVAC control system strategy using two-objective genetic algorithm," HVAC\&R Research 11(3):459-86.

[20]. Wang, S.W. 2006. Editorial: "Enhancing the applications of building automation systems for better building energy and environmental performance," HVAC\&R Research 12(2):197-99.

[21]. Wang, Shengwei, and Zhenjun Ma. "Supervisory and optimal control of building HVAC systems: A review," HVAC\&R Research 14, no. 1 (2008): 3-32.

[22]. Kanagaraj, N., P. Sivashanmugam, and S. Paramasivam. "A fuzzy logic based supervisory hierarchical control scheme for real time pressure control," International Journal of Automation and Computing 6, no. 1 (2009): 88-96.

[23]. Soyguder, Servet, Mehmet Karakose, and Hasan Alli. "Design and simulation of self-tuning PID-type fuzzy adaptive control for an expert HVAC system," Expert systems with applications 36, no. 3 (2009): 4566-4573.

[24]. Shepherd, A. B., and W. J. Batty. "Fuzzy control strategies to provide cost and energy efficient high-quality indoor environments in buildings with high occupant densities," Building Services Engineering Research and Technology 24, no. 1 (2003): 35-45.

[25]. Lianzhong, L., and M. Zaheeruddin. "Hybrid fuzzy logic control strategies for hot water district heating systems," Building Services Engineering Research and Technology 28, no. 1 (2007): 35-53.

[26]. Hussain, Sajid, and Hossam A. Gabbar. "A multi-objective evolutionary optimization of fuzzy controller for energy conservation in air conditioning systems," International Journal of Energy Research 38, no. 7 (2014): 847-859.

[27]. Lygouras, John N., P. N. Botsaris, J. Vourvoulakis, and Vassilis Kodogiannis. "Fuzzy logic controller implementation for a solar airconditioning system," Applied Energy 84, no. 12 (2007): 1305-1318. 
[28]. A. Abdo-Allah, T. Iqbal, andK. Pope, "Modeling and analysis of an HVAC system for the S.J. Carew Building at Memorial University," in Proceedings of the 30th IEEE Canadian Conference on Electrical and Computer Engineering (CCECE '17), pp. 1-4, IEEE, Windsor, Canada, May 2017

[29]. Abdo-Allah, Almahdi, Tariq Iqbal, and Kevin Pope. "Modeling, Analysis, and Design of a Fuzzy Logic Controller for an AHU in the SJ Carew Building at Memorial University,” Journal of Energy 2018 (2018).

[30]. Ljung, L. System identification Theory for the user, Second education, Prentice Hall PTR, (2006).

[31]. Afroz, Zakia, G. M. Shafiullah, Tania Urmee, and Gary Higgins. "Modeling techniques used in building HVAC control systems: A review," Renewable and Sustainable Energy Reviews 83 (2018): 64 84.

[32]. A. I. Dounis, M. J. Santamouris, C. C. Lefas, and A. Argiriou, "Design of a fuzzy set environment comfort system," Energy and Buildings, vol. 22, no. 1, pp. 81-87, 1995.

[33]. A. I. Dounis and D. E.Manolakis, "Design of a fuzzy system for living space thermal-comfort regulation," Applied Energy, vol. 69, no. 2, pp. 119-144, 2001

[34]. A. I. Dounis and C. Caraiscos, "Advanced control systems engineering for energy and comfort management in a building environment-a review," Renewable \& Sustainable Energy Reviews, vol. 13, no. 6-7, pp. 1246-1261, 2009.

[35]. Y. Bai and D. Wang, "Fundamentals of fuzzy logic control—fuzzy sets, fuzzy rules and defuzzifications," in Advances in Industrial Control, pp. 17-36, Springer, London, UK, 2006.

[36]. M. W. Khan, M. A. Choudhry, and M. Zeeshan, "Multivariable adaptive Fuzzy logic controller design based on genetic algorithm applied to HVAC systems," in Proceedings of the 3rd IEEE International Conference on Computer, Control and Communication (IC4 '13), pp. 1-6, September 2013.

[37]. Khan, Muhammad Waqas, Mohammad Ahmad Choudhry, and Muhammad Zeeshan. "An efficient design of genetic algorithm based adaptive fuzzy logic controller for multivariable control of hvac systems," In 2013 5th Computer Science and Electronic Engineering Conference (CEEC), pp. 1-6. IEEE, 2013.

[38]. Venayagamoorthy, Ganesh K., and Sheetal Doctor. "Navigation of mobile sensors using PSO and embedded PSO in a fuzzy logic controller," In Conference Record of the 2004 IEEE Industry Applications Conference, 2004. 39th IAS Annual Meeting., vol. 2, pp. 1200-1206. IEEE, 2004.

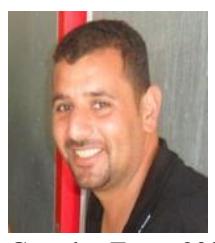

Almahdi Abdo-Allah received the B.S. (E.E.) degree from Sirte University Faculty of Engineering, Sirt, Libya, in 2003, the M.S. degree from Coventry University Faculty of Engineering and Computing, Coventry, West Midlands, UK, in 2010. And from 2015 to present I am Ph.D. student at Memorial University of Newfoundland: Saint John's, NL, Canada. From 2004 to 2008 and again from 2011 to 2014, I worked at University of Al Jabal Al Gharbi Zawia: Gharyan. Since 2015, I have been Ph.D. student at the Faculty of Engineering and Applied Science, Memorial University of Newfoundland, St. John's, NL, Canada. My research focuses on modeling and control of HVAC system.

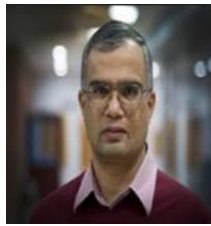

M. Tariq Iqbal received the B.S. (E.E.) degree from the University of Engineering and Technology, Lahore, Pakistan, in 1986, the M.S. degree in nuclear engineering from the Quaid-e-Azam University, Islamabad, Pakistan, in 1988, and the Ph.D. degree in electrical engineering from the Imperial College London, London, UK, in 1994. From 1988 to 1991 and again from 1995 to 1999 , he worked at the Pakistan Institute of Engineering and Applied Science, Islamabad, Pakistan. From 1999 to 2000, he worked as an Associate Professor at IIEC, Riphah International University, Islamabad, Pakistan. Since 2001, he has been working at the Faculty of Engineering and Applied Science, Memorial University of Newfoundland, St. John's, NL.

Presently, he is a Full Professor. His teaching activities cover a range of electrical engineering topics including electrical engineering design, control systems, renewable energy systems, and instrumentation. Currently, his research focuses on modeling and control of renewable energy systems with interests in the areas of design of control systems and comparison of control strategies of hybrid energy systems. http://www.engr.mun.ca/ tariq/.

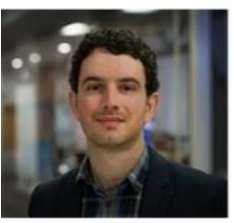

I studied at the University of Ontario Institute of Technology and obtained a BEng in Energy Systems Engineering (2008). My MASc thesis (2009) in Mechanical Engineering, involved the transient behaviour of wind turbines (Thermofluids and Microfluidics Laboratory), and my $\mathrm{PhD}$ thesis (2012) in Mechanical Engineering, focused on physiochemical characterization, multiphase flow and heat transfer for thermochemical energy conversion and storage (Clean Energy Research Laboratory). Before joining Memorial University, I investigated sustainable energy systems for large urban areas by examining the effects of different socioeconomic development pathways on resource demands and infrastructure needs.

During my research, I work closely with other major energy research institutions, including Nalcor, Statoil, Atomic Energy of Canada Limited, Argonne National Laboratory, Global Cities Indicators Facility and other research universities. I am a member of the American Institute for Aeronautics and Astronautics (AIAA) and the Canadian Society for Mechanical Engineering (CSME).

https://www.mun.ca/engineering/about/people/kevinpope.php 